\title{
IMMUNOMODULATORY ACTIVITY OF NUTRACEUTICAL FORMULATION AND ITS POTENTIATION BY SELF-FORTIFICATION AND COW URINE DISTILLATE FORTIFICATION METHODS
}

\author{
ANNAPURNA AKULA, CHANDI VISHALA, GUMMALLA PITCHAIAH* \\ College of Pharmaceutical Sciences, Andhra University, Visakhapatnam, Andhra Pradesh, India \\ Email: drgummalla@gmail.com
}

Received: 27 Jun 2016 Revised and Accepted: 19 Jun 2017

\begin{abstract}
Objective: This study prepared, evaluated immunomodulatory activity of nutraceutical formulation and studied the effect of self-mortification and cow urine distillate fortification methods on the immunomodulatory potential of nutraceutical formulation.

Methods: Three types of nutraceutical formulations i.e. Nutraceutical formulation (NF), self fortitfied nutraceutical formulation (SFNF) and self fortitfied nutraceutical formulation fortified with cow urine distillate (SFNECUD) were prepared using fine powders of amla, apple, garlic, onion, wheat grass, papaya, turmeric and cow urine distillate by different methods. The immunomodulatory activity of nutraceutical formulations at a dose of $500 \mathrm{mg} / \mathrm{kg}$ was assessed by various immune function parameters like cell-mediated immunity (neutrophil adhesion, delayed type hypersensitivity (DTH) response and cyclophosphamide-induced neutropenia), humoral immunity (serum immunoglobulins level and haemoagglutination antibody titer), and phagocytic activity (carbon clearance and polymorphonuclear (PMN) cell activity).
\end{abstract}

Results: Oral administration of NF, SFNF and SFNFCUD showed significant $(\mathrm{p}<0.01)$ increase in adhesion of neutrophils, potentiation of the DTH reaction and attenuation of cyclophosphamide-induced neutropenia. A significant increase in serum immunoglobulin levels and production of circulating antibody titer in response to sheep red blood cells (SRBCs) was also observed. In addition, an increase in the phagocytic index in carbon clearance assay and an increase in the phagocytic activity of PMN cells was observed.

Conclusion: From the above results, it can be concluded that all three types of formulations showed significant immunostimulant activity. SFNF and SFNFCUD showed better immunomodulatory activity than NF suggesting the potentiation of immunomodulatory potential of NF activity by fortification methods.

Keywords: Nutraceutical formulation, Fortification, Cell mediated immunity, Humoral immunity and Phagocytic activity

(C) 2017 The Authors. Published by Innovare Academic Sciences Pvt Ltd. This is an open access article under the CC BY license (http://creativecommons.org/licenses/by/4.0/) DOI: http://dx.doi.org/10.22159/ijpps.2017v9i8.13716

\section{INTRODUCTION}

Immunomodulation is an alteration of the immune system and interfering with its functions; if it results in an enhancement of immune reactions it is named as an immunostimulation which primarily implies stimulation of non-specific system, that is, granulocytes, macrophages, complement, certain T-lymphocytes and different effector substances. Immunosuppression implies mainly to reduce resistance against infections, stress and may occur on account of environmental or chemotherapeutic factors [1]. Immunostimulation and immunosuppression both need to be tackled in order to regulate the normal immunological functioning. Hence, both immune-stimulating agents and immunosuppressing agents have their own standing and search for better agents exerting these activities is becoming the field of major interest all over the world [2]

Natural adjuvants, synthetic agents, antibody reagents are used as immunosuppressive and immunostimulative agents. But there are a major limitation to the general use of these agents such as increased risk of infection and generalized effect throughout the immune system. Immunosuppression is a major drawback in the conventional therapy of cancer such as radiation and chemotherapy. Both this method have sever side effect such as nausea, vomiting, alopecia, mucosal ulceration etc. Modulation of immune responses to alleviate the diseases has been of interest for many years and the concept of 'Rasayana' in Ayurveda is based on related principles [3].

'Nutraceutical' is defined as a food or any part of food that gives a health benefit above and beyond providing simple nutrition. This generally accepted definition establishes that health benefit may include not only the prevention or treatment of disease but also a simple improvement in the body's immune system and performance. Further, it is also hypothesized that a combination of foods and/or multiple dietary agents may offer better therapeutic potential as compared to isolated compounds $[4,5]$.

Fortification refers to "the practice of deliberately increasing the content of essential components in a food irrespective of whether the nutrients were originally in the food before processing or not, so as to improve the quality of the food supply and to provide a public health benefit with minimal risk to health [6]. Therefore, the present study was designed to develop nutraceutical formulation with immunomodulatory potential and to study the effect of selfmortification and fortification with cow urine distillate methods on the immunomodulatory potential of prepared nutraceutical formulation.

\section{MATERIALS AND METHODS}

\section{Chemicals and reagents}

Drugs were procured; Levamisole (Khandelwal Pharmaceutical Ltd. Mumbai), Cyclophosphamide (Biochem Pharmaceutical, Mumbai), Colloidal carbon (Indian ink, camel India Pvt. Ltd.). All other reagents and chemicals were of analytical grade.

\section{Nutraceuticals}

All the nutraceuticals used in the preparation of formulations were of fine grade and collected from the local market.

Preparation of nutraceutical formulations

Nutraceutical Formulation (NF) was prepared by mixing fine dried powders of apple fruit, amla fruit, garlic bulbs, onion bulbs, papaya 
leaves, turmeric rhizomes and wheat grass in equal quantity. Self fortitfied nutraceutical formulation (SFNF) was prepared by using fine dried powders of self-fortified amla, self-fortified papaya, selffortified wheat grass along with apple, garlic, onion and turmeric powders. Self-fortification was done by deliberately fortifying the powder with their respective freshly prepared juice $(100 \mathrm{~g}$ of powder fortified with $50 \mathrm{ml}$ of juice) for three times before adding to the final formulation. Similarly, SFNFCUD was prepared by fortifying SFNF with cow urine distillate $(100 \mathrm{~g}$ of formulation fortified with $50 \mathrm{ml}$ of cow urine distillate each time).

\section{Animals}

Swiss albino mice of weighing 25-35 gm of either sex were used in the study and housed under good laboratory conditions. All the mice were fed with standard pellet diet (Nutrimix Std-1020, Nutrivet Laboratories, Pune) and water ad libitum. Animal experiments and handling were in accordance with CPCSEA guidelines, the prior permission for the study was obtained from "institutional animal ethical committee" (IAEC) (Registration no. 516/01/A/CPCSEA).

\section{Experimental groups and treatment}

The mice were divided into four groups consisting six animals in each.

Group I: Received sodium CMC $(0.1 \%$; p. o.) and served as vehicle control.

Group II: Received NF (500 mg/kg; p. o.)

Group III: Received SFNF (500 mg/kg; p. o.)

Group IV: Received SFNFCUD (500 mg/kg; p. o.)

\section{Preparation of SRBC antigen}

Fresh sheep blood was collected in Alsever's solution at the proportion of 1:1 ratio from local slaughter's house. The blood was centrifuged at $3000 \mathrm{rpm}$ for $15 \mathrm{~min}$ and serum is removed. The blood cells were washed for 2-3 times with phosphate buffered saline to remove plasma. Then the number of SRBC was then adjusted to a required concentration. The prepared SRBC antigen is stored at $4{ }^{\circ} \mathrm{C}$ [7].

\section{Neutrophil adhesion test}

After $14 \mathrm{~d}$ of treatment, blood samples were collected by puncturing the retro-orbital plexus into heparanized vials and analyzed for total leucocyte count (TLC) and differential leucocyte count (DLC) by fixing blood smears and staining with Field stain I and II Leishman's stain. After initial counts, blood samples were incubated with 80 $\mathrm{mg} / \mathrm{ml}$ of nylon fibres for $15 \mathrm{~min}$ at $37^{\circ} \mathrm{C}$. The incubated blood samples were again analyzed for TLC and DLC. The product of TLC and \% neutrophil gives neutrophil index (NI) of blood sample [8]. Percent neutrophil adhesion was calculated using fallowing formula.

$$
\text { Neutrophil adhesion }(\%)=\mathrm{NIu}-\mathrm{NIt} \text { X100/NIu }
$$

Where $\mathrm{NI}_{\mathrm{u}}=$ Neutrophil index of untreated blood samples $\mathrm{NI}_{\mathrm{t}}=$ Neutrophil index of treated blood sample.

\section{Delayed-type hypersensitivity (DTH) response}

In this method, mice were treated for $14 \mathrm{~d}$. On $7^{\text {th }}$ day of treatment, the mice were immunized with $0.1 \mathrm{ml}$ of SRBCs at a concentration of $0.5 \times 10^{9}$ cells $/ \mathrm{ml}\left(20 \%\right.$ SRBC) intraperitoneally (I. P). On $14^{\text {th }}$ day the mice were challenged with $0.03 \mathrm{ml}$ of $20 \%$ SRBCs in subplantar region of the right hind paw, and the same volume $0.03 \mathrm{ml}$ of saline was injected to the left hind paw which serves as control foot [9]. Foot pad reaction was assessed after $24 \mathrm{~h}$ using vernier caliper in terms of increase in the thickness of footpad as a result of edema. The footpad reaction was expressed as the difference in the thickness $(\mathrm{mm})$ between the right footpad injected with SRBC and the left footpad injected with normal saline. Cyclophosphamide-induced neutropenia in this method treatment was given for $14 \mathrm{~d}$. On $14^{\text {th }}$ day after $3 \mathrm{~h}$ of treatment, a neutropenic dose of cyclophosphamide $(200 \mathrm{mg} / \mathrm{kg}$, S. C.) was injected and this day was marked as the first day. Prior to injection blood samples were collected and the total leukocytes count and differential leukocytes count were estimated by using haemo analyser. Again on $3^{\text {rd }}$ day after injection, the TLC and neutrophil counts (\%) were estimated [10]. Effect on serum immunoglobulins All the groups were treated for $21 \mathrm{~d}$. Six hours after the last dose of the drug, blood was collected and the serum was used for estimation of immunoglobulin levels using a method devised by Mullen et al., 1975 [11]. Briefly, for each serum sample to be analyzed, a control tube containing $6 \mathrm{ml}$ of distilled water and a test tube containing $6 \mathrm{ml}$ of zinc sulphate solution was prepared. To each, $0.1 \mathrm{ml}$ of serum was added from a pipette [12].

\section{Hemagglutination antibody (HA) titer}

All the animals were treated for $21 \mathrm{~d}$. On $7^{\text {th }}$ and $14^{\text {th }}$ day of the study, mice from all the groups (i.e. group I to VIII) were immunized and challenged respectively, with SRBCs in normal saline $(0.1 \mathrm{ml}$ of $20 \%$ SRBCs) intraperitoneally. Blood was withdrawn on $14^{\text {th }}$ and $21^{\text {st }}$ day from retro-orbital plexus under mild ether anaesthesia from all antigenically sensitised and challenged mice respectively. Blood was centrifuged to obtain serum, normal saline was used as a diluent and the SRBCs count was adjusted to $(0.1 \%$ of SRBCs). Each well of a microtiter plate was filled initially with $20 \mu \mathrm{l}$ of saline and $20 \mu \mathrm{l}$ of serum was mixed in the first well of microtiter plate. Subsequently, the $20 \mu \mathrm{l}$ diluted serum was removed from first well and added to the next well to get twofold dilutions of the antibodies present in the serum. Further twofold dilutions of this diluted serum were similarly carried out till the last well of the second row (24th well) so that the antibody concentration of any of the dilutions is half of the previous dilution. $20 \mu \mathrm{l} \mathrm{SRBC} \mathrm{(0.1 \%} \mathrm{of} \mathrm{SRBCs)} \mathrm{were} \mathrm{added} \mathrm{to} \mathrm{each} \mathrm{of}$ these dilutions and the plates were incubated at $37^{\circ} \mathrm{C}$ for one hour and then observed for haemagglutination. The highest dilution giving haemagglutination was taken as the antibody titer. The antibody titers were expressed in a graded manner, the minimum dilution $(1 / 2)$ being ranked as 1 , and mean ranks of different groups were compared for statistical significance. Antibody titer obtained on 14th day after immunization (on $7^{\text {th }}$ day) and on $21^{\text {st }}$ day after challenge (on $14^{\text {th }}$ day) with SRBCs was considered as primary and secondary humoral immune response respectively $[13,14]$.

\section{Carbon clearance test}

The colloidal carbon ink or Indian ink was diluted with PBS (pH 7.4) to eight times before using at a dose of $10 \mu \mathrm{l} / \mathrm{gm}$ of body weight of mice. In this method, treatment was given for $14 \mathrm{~d}$. After $3 \mathrm{~h}$ of last treatment, the mice of all groups were injected with indian ink at a dose of $10 \mu \mathrm{l} / \mathrm{gm}$ of body weight via the tail vein. Blood samples were collected by retro-orbital plexus method at the intervals of 0 and $15 \mathrm{~min}$. Blood samples $(25 \mu \mathrm{l})$ was mixed with $3 \mathrm{ml}$ of $0.1 \%$ sodium carbonate solution and absorbance was determined at 660 $\mathrm{nm}$ by using spectrophotometer [15].

The phagocytic index was calculated using the following formula

$$
\mathrm{K}=\log \mathrm{OD} 1-\log \mathrm{OD} 2 / \mathrm{t} 2-\mathrm{t} 1
$$

Where, $\mathrm{OD}_{1}$ and $\mathrm{OD}_{2}$ are the optical densities at time $\mathrm{t}_{1}$ and $\mathrm{t}_{2}$ respectively.

\section{Phagocytic activity of polymorph nuclear (PMN) cells}

In this method, treatment was given for $14 \mathrm{~d}$ and on $15^{\text {th }}$ day blood sampling was performed and two drops of blood were collected on a clean glass slide and allowed to dry for $5 \mathrm{~min}$ at room temperature which permits to clot. The clot was gently removed by washing under running tap water, by leaving a thin layer of cells to adhere the glass slide. This layer of cells are known as PMN cells, which are covered by a layer of Candida albicans (yeast cells $10^{6}$ cells $/ \mathrm{ml}$ ) and incubated for $1 \mathrm{~h}$. at $37^{\circ} \mathrm{C}$. The slide was then stained with Giemsa stain and observed under a microscope for phagocytosis of PMN cells. Phagocytic activity was expressed as the average number of Candida per PMN [16].

\section{Statistical analysis}

The results were expressed as mean \pm SEM (standard error mean) and statistical analysis was carried out using one-way ANOVA followed by Dunnett's test. The P-value $<0.05$ is considered statistically significant.

\section{RESULTS}

\section{Neutrophil adhesion test}

In the current study, a significant increase in neutrophil adhesion at a dose of $500 \mathrm{mg} / \mathrm{kg}$ was observed with 
nutraceutical formulation (NF). Further, a more significant increase in neutrophil adhesion was seen with SFNF and SFNFCUD. The \% neutrophil adhesion in control group animals was 20.4, in NF treated group animals, it was 32.7 whilst for SFNF and SFNFCUD treated group animals, it was 40.4 and 50.1 respectively. The results were given in the table 1 .

Table 1: Effect of neutraceutical formulations on neutrophil adhesion

\begin{tabular}{llll}
\hline Treatment & Neutrophil index & Neutrophil adhesion (\%) \\
\cline { 2 - 3 } & UB & NFTB & 20.4 \\
Vehicle control & $312.5 \pm 14.1$ & $248.7 \pm 7.8$ & $32.7^{*}$ \\
NF (500 mg/kg) & $402.3 \pm 16.7$ & $270.9 \pm 9.5$ & $40.4^{* *}$ \\
SFNF (500 mg/kg) & $421.7 \pm 17.8$ & $251.3 \pm 13.2$ & $50.1^{* * *}$ \\
SFNFCUD (500 mg/kg) & $481.4 \pm 13.4$ & $239.8 \pm 12.1$ & \\
\hline
\end{tabular}

Values are mean \pm SEM, $\mathrm{n}=6$ in each group. The $\mathrm{P}^{* * *}<0.001, \mathrm{P}^{* *}<0.01$ and $\mathrm{P}^{*}<0.05$, are statistically significant.

\section{Delayed-type hypersensitivity reaction}

In delayed type hypersensitivity reaction model, treatment with nutraceutical formulation (NF) showed a significant increase in paw edema and percentage of inflammation. The SFNF and SFNFCUD showed more significant activity than NF when compared with control. The results were shown in the table 2 .

\section{Cyclophosphamide-induced neutropenia}

Pretreatment with NF before cyclophosphamide administration showed a significant protection against cyclophosphamide-induced neutropenia when compared with the control group. Similarly, Pretreatment with SFNF and SFNFCUD showed more significant protection than NF when compared with control. The results were given in the table 2 .

Table 2: Effect of nutraceutical formulation on cell-mediated immunity (CMI)

\begin{tabular}{llll}
\hline Treatment & $\begin{array}{l}\text { DTH response } \\
\text { (Mean difference in paw edema(mm)) }\end{array}$ & \multicolumn{3}{c}{ Cyclophosphamide-induced neutropenia } \\
\cline { 2 - 4 } & $0.74 \pm 0.08$ & Reduction in TLC (\%) & Reduction in neutrophil count (\%) \\
\hline Vehicle control & $1.39 \pm 0.11^{* *}$ & 36.3 & 62.6 \\
NF $(500 \mathrm{mg} / \mathrm{kg})$ & $2.49 \pm 0.14^{* *}$ & $28.7^{* * *}$ & $41.7^{* *}$ \\
SFNF $(500 \mathrm{mg} / \mathrm{kg})$ & $2.82 \pm 0.09^{* *}$ & $20.2^{* * *}$ & $30.6^{* * *}$ \\
SFNFCUD $(500 \mathrm{mg} / \mathrm{kg})$ & & $24.6^{* * *}$ \\
\hline
\end{tabular}

Values are mean \pm SEM, $\mathrm{n}=6$ in each group. The $\mathrm{P}^{* * *}<0.001 \mathrm{P}^{* *}<0.01$ and $\mathrm{P}^{*}<0.05$, are statistically significant.

\section{Serum immunoglobulin level}

Administration of NF showed a significant increase in the serum immunoglobulin levels when compared with the control. Further, SFNF and SFNFCUD treated animals showed a greater increase in serum immunoglobulins levels. The percentage of increase in serum immunoglobulins levels in NF treated mice was 39.4. Whereas in SFNF and SFNFCUD treated animals, it was 47.5 and 52.8 respectively. The results were illustrated in the table 3.

\section{Hemagglutination antibody titer}

Nutraceutical Formulation (NF) treated mice showed a significant rise in hemagglutination titer value of both primary and secondary immunity when compared with the control group. Similarly, SFNF treated mice showed more significant activity in both primary and secondary immunity when compared with control. The SFNFCUD showed even more significant activity than SFNF. The results were given in the table 3.

Table 3: Effect of nutraceutical formulations on humoral immunity

\begin{tabular}{|c|c|c|c|}
\hline \multirow[t]{2}{*}{ Treatment } & \multirow[t]{2}{*}{ Serum immunoglobulins level (Turbidity units) } & \multicolumn{2}{|c|}{ Hemagglutination titer values } \\
\hline & & Primary immunity & Secondary immunity \\
\hline Vehicle control & $12.34 \pm 0.62$ & $7.16 \pm 0.13$ & $7.5 \pm 0.19$ \\
\hline $\mathrm{NF}(500 \mathrm{mg} / \mathrm{kg})$ & 17. $2 \pm 2.5^{*}$ & $7.98 \pm 1.03^{*}$ & $8.52 \pm 1.51^{*}$ \\
\hline SFNF $(500 \mathrm{mg} / \mathrm{kg})$ & $23.546 \pm 1.52 * *$ & $8.33 \pm 0.16^{*}$ & $9.33 \pm 0.16^{* *}$ \\
\hline SFNF CUD (500 mg/kg) & $26.16 \pm 1.05^{* * *}$ & $9.16 \pm 0.13^{* *}$ & $12.5 \pm 0.19 * *$ \\
\hline
\end{tabular}

Values are mean \pm SEM, $\mathrm{n}=6$ in each group. The $\mathrm{P}^{* * *}<0.001 \mathrm{P}^{* * *}<0.01$ and $\mathrm{P}^{*}<0.05$, are statistically significant.

Table 4: Effect of nutraceutical formulations on phagocytic activity

\begin{tabular}{lll}
\hline Treatment & Phagocytic index & PMN cells activity (no. of candida/PMN) \\
\hline Vehicle control $(0.1 \%$ Sodium CMC) & $0.0054 \pm 0.0013$ & $3.36 \pm 0.05$ \\
NF & $0.0101 \pm 0.002^{*}$ & $4.03 \pm 0.08^{*}$ \\
SFNF $(500 \mathrm{mg} / \mathrm{kg})$ & $0.0131 \pm 0.004^{* *}$ & $4.15 \pm 0.06^{* *}$ \\
SFNFCUD $(500 \mathrm{mg} / \mathrm{kg})$ & $0.0181 \pm 0.001^{* * *}$ & $4.7 \pm 0.052^{* *}$ \\
\hline
\end{tabular}

Values are mean \pm SEM, $\mathrm{n}=6$ in each group. The $\mathrm{P}^{* * *}<0.001 \mathrm{P}^{* *}<0.01$ and $\mathrm{P}^{*}<0.05$, are statistically significant.

\section{Carbon clearance test}

A significant increase in phagocytic activity was observed in NF, SFNF and SFNFCUD treated groups when compared with control group. The SFNF and SFNFCUD showed more significant activity than NF when compared with control. The results were given in the table 4

\section{Phagocytosis of PMN Cells}

$\mathrm{NF}$ treatment showed a significant increase in phagocytic activity against Candida albicans when compared with the control group. The SFNF and SFNFCUD showed a more significant increase in phagocytic activity against Candida albicans when compared with the control group. The results were given in table 4 . 


\section{DISCUSSION}

Neutrophils circulate in the vasculature in a passive state and become more adhesive upon stimulation at sites of inflammation, while it was marginated to the vessel wall, subsequently by transmigration and phagocytosis [17]. In the present study, all three nutraceutical formulations when administered orally at $500 \mathrm{mg} / \mathrm{kg}$ body weight significantly increased the recruitment of neutrophils adhesion to nylon fibres which correlate to the process of margination of cells in blood vessels. In delayed type hypersensitivity (DTH) reaction test, the DTH response directly correlates with cell-mediated immunity (CMI). The mechanism behind this elevated DTH during the CMI responses could be due to sensitized T lymphocytes. During immunization when an antigen is recognized by the Th1 cells secretes cytokines which in turn increases the vascular permeability, vasodilation, activation of macrophages and also colony formation with class II MHC molecules. On subsequent challenging with the same antigen even in the trivial amount, the Th1 cells secrete cytokines, activate macrophages and other non-specific inflammatory mediators and produces swelling, redness etc $[18,19]$. In our present investigation, DTH response was significantly increased by nutraceutical formulation (NF) and potentiated by both the fortification methods suggesting the stimulation of cell-mediated immunity.

Cyclophosphamide is an important anticancer drug which acts by causing alkylation of DNA. The main side effect of cyclophosphamide is bone marrow depression leads to neutropenia. The immunestimulants significantly enhances the bone marrow functions and reducing the side effects of various anticancer drugs [10]. In the present study, the nutraceutical formulations exhibited significant protection against cyclophosphamide-induced neutropenia, suggesting that nutraceutical formulations may also have an effect on the haematopoietic system.

The estimation of serum immunoglobulin level is a direct measure to detect the humoral immunity. Immunoglobulins are the proteins which are produced by B-lymphocytes, these are also known as antibodies as they fight against antigens. Zinc sulphate causes precipitation of the immunoglobulin making the solution cloudy. The extent of turbidity indicates the immunoglobulin level in serum [11]. In our study, all the test formulations increased the serum immunoglobulin levels suggesting the immunostimulant potential of nutraceutical formulations.

Antibodies are the effectors of the humoral response when an animal is immunized with an antigen the antibodies are released in response to antigen. The released antibodies are of two types they are active and inactive antibodies. The active antibodies immediately interact with the antigen which is known as primary immunity. The inactive antibodies are called "Memory antibodies" which are released in large amounts when an animal is exposed with the same antigen even in trivial amounts, which is known as secondary immunity [20]. The high values of haemagglutinating antibody titer (primary and secondary) obtained in the case of nutraceutical formulations have indicated that immunostimulation was achieved through humoral immunity.

Phagocytosis is the mechanism of removal of microorganisms, foreign bodies etc. from the body. Macrophages play an important role in phagocytosis. The reticuloendothelial system is the best defined functionally by its ability to scavenge debris or other foreign matter and forms the first line of defence. The rate of removal of carbon particles, by the sessile intravascular phagocytes in the liver and spleen, from the bloodstream, is a measure of reticuloendothelial phagocytic activity. In carbon clearance test; nutraceutical formulations treated groups exhibited significantly high phagocytic index. This indicates stimulation of the reticuloendothelial system by nutraceutical formulations treatment $[21,22]$. The polymorphonuclear phagocytes (which include neutrophils, basophils, and eosinophils) are of key importance in the containment of infection. Neutrophils, in particular, are specialized killer cells which destroy the microbial prey by releasing various cytokines [23]. In the present investigation, nutraceutical formulations treated groups showed significant engulfment of the Candida albicans per PMN cells suggesting the immunostimulant property of nutraceutical formulations. The order of immunestimulant activity of nutraceutical formulations was NF> NFCUD> SFNFCUD.

\section{CONCLUSION}

From the results of this study, it can be concluded that the combination nutraceuticals like amla, apple, papaya, turmeric, wheatgrass, onion and garlic acted synergistically evidenced by stimulation of not only non-specific immune response but also stimulation of humoral immunity and cell-mediated immunity by nutraceutical formulation (NF) when administered orally at a dose level of $500 \mathrm{mg} / \mathrm{kg}$. Further, SFNF and SFNFCUD treatment resulted in even more immunostimulant activity suggesting the potentiation of immunostimulant activity of nutraceutical formulation by the selffortification process and cow urine distillate fortification. Further studies are also warranted for understanding the exact mechanisms responsible for the immunomodulatory potential of $\mathrm{NF}$ and its potentiation by self-mortification and cow urine distillate fortification process.

\section{ACKNOWLEDGMENT}

Authors are sincerely thanking Technoprenuer promotion programme (TePP), Under TPDU programme, Department of Science and Industrial Research (DSIR) for funding this work and Andhra University for providing timely support. I am very much thankful to my guide Prof. A Annapurna for her guidance, kind help and constant encouragement at every step during the progress of work.

\section{CONFLICTS OF INTERESTS}

\section{All authors have none to declare}

\section{REFERENCES}

1. Makare N, Bodhankar S, Rangari V. Immunomodulatory activity of alcoholic extract of Mangifera indica L. in mice. J Ethnopharmacol 2001;78:133.

2. Patwardhan B, Kalbag D, Patki PS, Nagsampagi BA. Search of immunomodulatory agents: a review. India Drugs 1990;28:348-58.

3. Premanathan M, Rajendran S, Ramanathan T, Kathiresan $K$, Nakashima H, Yamamoto N. A survey of some Indian medicinal plants for anti-human immunodeficiency virus (HIV) activity. Indian J Med Res 2000;112:73-7.

4. Brower V. Nutraceuticals: poised for a healthy slice of the healthcare market? Nat Biotechnol 1998;16:728-31.

5. Philippe R, Colin W, Wright, Merlin L Willcox, Ben Gilbert. Whole plant extracts versus single compounds for the treatment of malaria: synergy and positive interactions. Malaria J 2011;10:S4

6. Allen L, de Benoist B, Dary O, Hurrell R. World Health Organization, food and agricultural organization of the united nations. Guidelines on food fortification with micronutrients. Geneva, Switzerland; 2006.

7. Patil PR, Patil MR, Mane A, Patil S. Immunomodulatory effects of fruits of Barringtonia racemosa Linn. Int J Basic Clin Pharmacol 2013;2:216-9.

8. Wilkinson PC, Vane JK, Ferreria SH. Handbook of experimental pharmacology, Berlin: Springer-Verlag; 1978. p. 109.

9. Karthikumar S, Jegatheesan K, Thangaraja A, Banupriya K, Dhivya T, Malarvizhi JM. Immunomodulatory activity of Eclipta prostrata in SRBC immunized mice. J Pharmacogn Phytochem 2011;3:52-5.

10. Thatte UM, Chhabria SN, Karandikar SM, Dahanukar SA. Protective effects of Indian medicinal plants against cyclophosphamide neutropenia. J Postgrad Med 1987; 33:185-8.

11. Mullen PA. Zinc sulphate turbidity test as an aid to diagnosis. Veter Ann 1975;15:451-5.

12. Sedlinsk M, Krej J, Vysko M. Evaluation of field methods for determining immunoglobulins in Sucking Foals. Acta Vet Brno 2005;74:51-8.

13. Mitra SS. Immunomodulatory effect of IM-133. Phytother Res 1999;13:341-3. 
14. Puri A, Saxena RP, Saxena KC. Immunostimulant agents from Andrographis peniculata. J Nat Prod 1993;56:995-9.

15. Das M, Dasgupta SC, Gomes . The immunomodulatory and antineoplastic activity of common Indian plants. Indian J Physiol Pharmacol 2009;53:311-7.

16. Daswani BR, Radha Yegnanarayan. Immunomodulatory activity of septilin, a polyherbal preparation. Phytother Res 2002;16:162-5.

17. Vinothapooshan G, Sundar K. Immunomodulatory activity of various extracts of Adhatoda vasica Linn. in experimental rats. Afr J Pharm Pharmacol 2011;5:306-10.

18. Rao CV. Immunology. Introduction, India: Rajkamal Electric Press; 2006.

19. Miller LE, Ludke HR, Peacock JE, Tomar RH. Manual of laboratory Immunology. Lea and Febiger; 1991. p. 1-18.

20. Kadry MS. Antioxidant and immunostimulant effect of Carica papaya Linn. aqueous extract in acrylamide intoxicated rats. Acta Inform Med 2012;20:180-5.
21. Gokhale $\mathrm{AB}$, Damre AS, Saraf MN. Investigations into the immunomodulatory activity of Argyreia speciosa. I Ethnopharmacol 2003;84:109-14.

22. Feng ZH, Zhang GM, Hao TL, Zhou B, Zhang H, Jiang ZY. Effect of diallyl trisulfide on activation of T-cells and macrophage-mediated cytotoxicity. J Tongji Med Univ 1994;14:142-7.

23. Bruce Beutler. Innate immunity: an overview. Mol Immunol 2004;40:845-59.

\section{How to cite this article}

- Annapurna Akula, Chandi Vishala, Gummalla Pitchaiah. Immunomodulatory activity of nutraceutical formulation and its potentiation by self-mortification and cow urine distillate fortification methods. Int J Pharm Pharm Sci 2017;9(8):15-19. 